\title{
Formula for Academic Success in the First Year
}

\author{
By Thomas A. Power, ACSW \\ Published by Elan Publishing 2004
}

Reviewed by

Suzanne J. Price (mjprice@ clemson.edu), Director of Leadership Programs, Clemson University

Students entering college can become overwhelmed with the obligations, freedoms, and expectations of higher education. First-year students in particular may face uncertainties not previously experienced in high school. Academic and personal success can be difficult to define and establish without adequate guidance and support. Power's Formula for Academic Success in the First Year offers several straightforward steps for coping with these uncertainties and developing effective strategies for academic and personal success in college.

The introductory section of the guide clearly states the author's intent - to relay information that encourages and challenges students to be as successful as they want. Power defines the terms "success" and "strategy," encouraging the student to first define personal success and then develop a strategy for attaining the desired outcomes. Perhaps recognizing that completing these tasks is not as easily accomplished as one may think, Power describes the internal battle of our "inner voices." He describes the positive and negative competing voices as the "drunken monkey," explaining that the voices are constantly chattering and may also be unreliable. Power's intent to accurately depict the decision-making process of a new student is valiant, but his choice of terminology is somewhat disconcerting. While the process described is quite accurate, his use of the term "drunken monkey" may not be appropriately utilized by the typical first-year student. In fact, some may find it more juvenile than descriptive and lose interest in the rest of the guide.

Power introduces the process for developing strategies for success by offering four important points for students to consider. First, he encourages students to use all resources available to them. Next, students are directed to develop a plan of action for accomplishing specific goals. The final two points challenge students to develop strategies that limit the power of the negative voice and to prepare to stick with determined strategies. In perhaps the most important section of the guide, Power offers examples and suggestions for overcoming the negative messages encouraged by the negative voice. Clearly addressing the negative and self-defeating voices with examples validates the concerns of many first-year students and directs them in recognizing and defeating the negative messages. Common obstacles for defeating negative messages are covered and include results and excuses, time management and self-management, and procrastination. These obstacles are obvious ones that often hinder student success. Including an explicit discussion about each of them is important as first-year students in particular may have difficulty overcoming these obstacles and becoming as successful as 
they can be.

Power identifies strategies for self-management in the next section of the guide. As he explains, each strategy can help students manage the negative voice. The first step is to give your word and keep it. By giving one's word (to others and self) the desire to follow through and stay committed becomes stronger. In addition, not following through can lead to more self-defeating practices. While this strategy may seem somewhat traditional, the consequences for failing to recognize the value of keeping one's word can be quite costly for students. I applaud Power's inclusion of a traditional, yet necessary, component of success.

Additional strategies include awareness of the negative voice, self-discipline, communication, and building a support system. As Power describes, a lack of awareness of the negative voice may leave students vulnerable to its influences. Self-discipline is essential for combating the negative voice and developing positive results. In this section, he cautions against overuse of the term "try" as he warns that it may cause students to fall short of their original goals. Clear communication is an important strategy as students must be able to communicate their needs and concerns to those who can help. Finally, Power addresses the need for a positive and selective support network. Perhaps more easily said than done, many new students may find selectivity and patience difficult to achieve during those early and critically important social weeks of school.

Power concludes the guide with a step-by-step process for developing a systematic and strategic format for success. Using the goal of getting places on time, he moves through each stage of the process showing students how to achieve success. With a final plea for intrinsic motivation, Power reminds students that promises made to oneself are just as important as those made to others and that failure to meet those promises can lead to self-sabotage. The remaining few pages of the guide provide five templates for students to use to determine their own goals and to complete the steps for success, as well as a few pages for notes.

Formula for Academic Success in the First Year provides new students a clear and concise plan for achieving success in college. Although some of his terminology and examples are a bit juvenile, his message and process are appropriate for the new student entering the college environment. The guide would be an excellent companion piece for any first-year seminar or academic success course. The strategies and suggestions in the guide also may be useful for resident assistants or mentors who work specifically with new students. 